\title{
A simple calculation for the preoperative estimation of transverse rectus abdominis myocutaneous free flap volume in 2-stage breast reconstruction using a tissue expander
}

\author{
Hikaru Kono ${ }^{1}$, Naohiro Ishii ${ }^{1}$, Masayoshi Takayama ${ }^{2}$, Masashi Takemaru ${ }^{1}$, Kazuo Kishi ${ }^{1}$ \\ ${ }^{1}$ Department of Plastic and Reconstructive Surgery, Keio University School of Medicine, Tokyo; ${ }^{2}$ Department of Plastic and Reconstructive \\ Surgery, Nasu Red Cross Hospital, Otawara, Japan
}

Background Flap volume is an important factor for obtaining satisfactory symmetry in breast reconstruction with a transverse rectus abdominis myocutaneous (TRAM) free flap. We aimed to develop an easy and simple method to estimate flap volume.

Methods We performed a preoperative estimation of the TRAM flap volume in five patients with breast cancer who underwent 2-stage breast reconstruction following an immediate tissue expander operation after a simple mastectomy. We measured the height and width of each flap zone using a ruler and measured the tissue thickness by ultrasound. The volume of each zone, approximated as a triangular or square prism, was then calculated. The zone volumes were summed to obtain the total calculated volume of the TRAM flap. We then determined the width of zone II, so that the calculated flap volume was equal to the required flap volume $(1.2 \times 1.05 \times$ the weight of the resected mastectomy tissue). The TRAM flap was transferred vertically so that zone III was located on the upper side, and zone II was trimmed in the sitting position after vascular anastomosis. We compared the estimated flap width of zone II ( $=$ X) with the actual flap width of zone II.

Results $\mathrm{X}$ was similar to the actual measured width. Accurate volume replacement with the TRAM flap resulted in good symmetry in all cases.

Conclusions The volume of a free TRAM flap can be straightforwardly estimated preoperatively using the method presented here, with ultrasound, ruler, and simple calculations, and this technique may help reduced the time required for precise flap tailoring.

Keywords Breast / Diagnostic imaging / Mammaplasty / Mammary glands / Mastectomy
Correspondence: Naohiro Ishii Department of Plastic and Reconstructive Surgery, Keio University School of Medicine, 35 Shinanomachi, Shinjuku-ku, Tokyo 160-8582, Japan

Tel: $+81-3-5363-3814$

Fax: +81-3-3352-1054

E-mail: ishina00916@gmail.com

Received: 14 Sep 2017 • Revised: 17 Jan 2018 • Accepted: 25 Jan 2018

pISSN: 2234-6163 • elSSN: 2234-6171 • https://doi.org/10.5999/aps.2017.01473 • Arch Plast Surg 2018;45:333-339

\section{INTRODUCTION}

The transverse rectus abdominis myocutaneous (TRAM) free flap is commonly used for breast reconstruction, since the flap elevation procedure is safe and well-established and the survival rates of TRAM flaps are acceptable [1-3]. Furthermore, TRAM flap elevation can be performed simultaneously with the removal of the expander and dissection of internal thoracic vessels. In

Copyright (C) 2018 The Korean Society of Plastic and Reconstructive Surgeons

This is an Open Access article distributed under the terms of the Creative Commons Attribution Non-Commercial License (http://creativecommons.org/

licenses/by-nc/4.0/) which permits unrestricted non-commercial use, distribution, and reproduction in any medium, provided the original work is properly cited.

www.e-aps.org 
order to obtain satisfactory outcomes in breast reconstruction procedures using a flap, symmetrical volume is essential. However, it is generally difficult to estimate flap volume before elevation. The preoperative estimation of flap volume improves the flap design and the ease of intraoperative flap volume adjustments. Recently, several studies have investigated the measurement of flap volume using computed tomography (CT) [4-6] and the pinch test [7]. However, the most appropriate technique for preoperatively estimating TRAM flap volume with the goal of achieving symmetrical breasts remains to be unclarified.

We aimed to develop a method of preoperative TRAM flap volume estimation and flap volume tailoring using a simple calculation based on measurements of the abdominal skin and subcutaneous tissue thickness made using ultrasound.

\section{METHODS}

We performed a preoperative estimation of the TRAM flap volume in five patients with breast cancer who underwent 2-stage breast reconstruction using a TRAM flap following an immediate tissue expander operation after a simple mastectomy through a transverse incision between April 2016 and January 2017. Table 1 presents the characteristics of all patients included in this study. No patients had a history of radiation therapy. Postoperative adjuvant chemotherapy was performed in two cases. None of the patients in the present study had a weight increase or decrease of $\geq 2 \mathrm{~kg}$ in the follow-up period. There were no obvious preoperative differences between the breasts on the affected side and the contralateral breasts, and no differences were observed between the contralateral breasts with the expander inserted and the breasts that were reconstructed with a TRAM flap. The height, width, and projection of the breasts were measured by a caliper and the breasts were also visually examined using photographs. We inserted the expander $3 \mathrm{~cm}$ below the inframammary fold (IMF) of the contralateral breast and performed expander replacement with a TRAM flap at least 3 months after the sa- line injection of the expander was completed.

\section{Preoperative design and measurement of the TRAM flap}

We determined the height of the flap needed to suture and close the tissue of the donor site without difficulty. The width was the distance between the bilateral anterior iliac spines. The TRAM flap was divided into four zones preoperatively in the usual manner (Fig. 1). The flap was located vertically so that zone III was on the upper side. The height of the flap was shorter than the width of the contralateral breast, and therefore, an adipose flap under the superficial fascia was added on the upper side and lower side of the flap to compensate for this difference. We measured the height and width of each zone using a ruler and measured the thickness of the skin and subcutaneous tissue by ultrasound in the supine position. Ultrasound B-mode images were

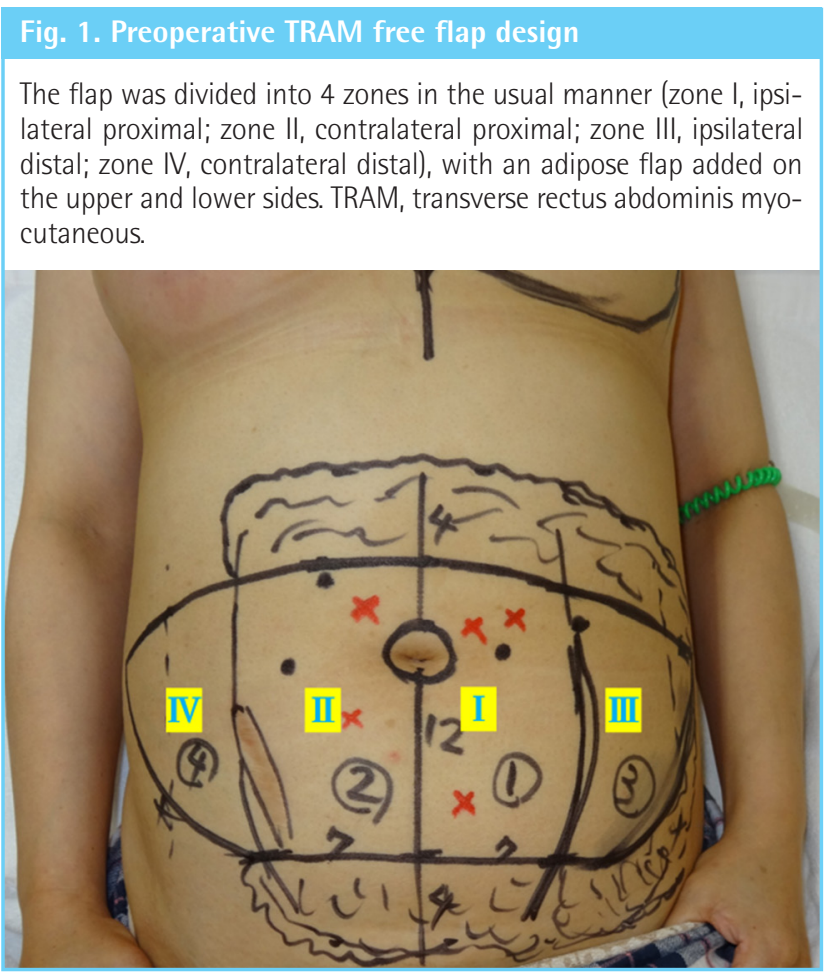

\begin{tabular}{|c|c|c|c|c|c|c|c|c|}
\hline Case & $\begin{array}{c}\mathrm{BMI} \\
\left(\mathrm{kg} / \mathrm{m}^{2}\right)\end{array}$ & $\begin{array}{l}\text { Height } \\
(\mathrm{cm})\end{array}$ & $\begin{array}{l}\text { Width } \\
(\mathrm{cm})\end{array}$ & $\begin{array}{l}\text { Projection } \\
\text { (cm) }\end{array}$ & $\begin{array}{l}\text { RW } \\
(\mathrm{g})\end{array}$ & $\begin{array}{l}\text { Full saline } \\
\text { volume }(\mathrm{mL})\end{array}$ & $\begin{array}{c}\text { MS } \\
\text { classification }\end{array}$ & $\begin{array}{l}\text { Follow-up } \\
\text { period (mo) }\end{array}$ \\
\hline 1 & 21.0 & 11.5 & 12.0 & 3.0 & 280 & 350 & MS-3 & 16 \\
\hline 2 & 26.0 & 11.5 & 14.0 & 5.2 & 671 & 750 & MS-1 & 14 \\
\hline 3 & 23.5 & 12.0 & 14.0 & 4.2 & 418 & 450 & MS-1 & 12 \\
\hline 4 & 25.0 & 13.0 & 13.5 & 4.2 & 384 & 550 & MS-1 & 9 \\
\hline 5 & 27.2 & 12.5 & 14.5 & 7.9 & 712 & 790 & MS-1 & 7 \\
\hline
\end{tabular}

Height was defined as the maximum vertical length of the contralateral breast, width as the maximum horizontal length of the contralateral breast, and projection as the distance vertical to chest wall between the nipple base and the chest wall.

BMl, body mass index; RW, weight of resected tissue from the mastectomy; MS, muscle-sparing. 
obtained using a SSA-790A apparatus (Toshiba Medical, Tokyo, Japan) equipped with a $3.5-\mathrm{MHz}$ convex probe. In accordance with the report of Yano et al. [8], the site of maximum thickness was $2 \mathrm{~cm}$ below the umbilicus and the site of minimum thickness was near the inferior margin of the flap. We defined the thickness of zone I and II as the average thickness of these two sites. The thickness of zone III and of the adipose flap was measured at the center of each site. We ensured that the probe was used without skin compression so that inter-examiner variance was minimized. The corresponding author made the measurements in all cases.

\section{Adjustment of flap volume by trimming zone II}

Zone IV was excised, and the flap volume was then adjusted by trimming zone II. The width of zone II after trimming was defined as X (Fig. 2). We calculated the volume of each zone and of the adipose flap (estimated flap volume), approximated as a square or triangular prism. Considering postoperative flap atrophy, we determined that the required flap volume was 1.2 times the volume of the tissue resected during mastectomy. According to the report of Minn et al. [9], the mastectomy volume was defined as 1.05 times the mastectomy weight. We used the following equation to determine the amount of preoperative trimming of zone II that was required: calculated flap volume (fixed flap volume [zone I+zone III+adipose flap (zone I, III)]+trimmed flap volume [zone II+adipose flap (zone II)] $)=$ required flap volume, that is, $1.2 \times 1.05 \times$ the weight of the resected mastectomy tissue.

\section{Fig. 2. Definition of $X$}

When the flap was aligned vertically, the width of zone II after trimming was defined as $X$.

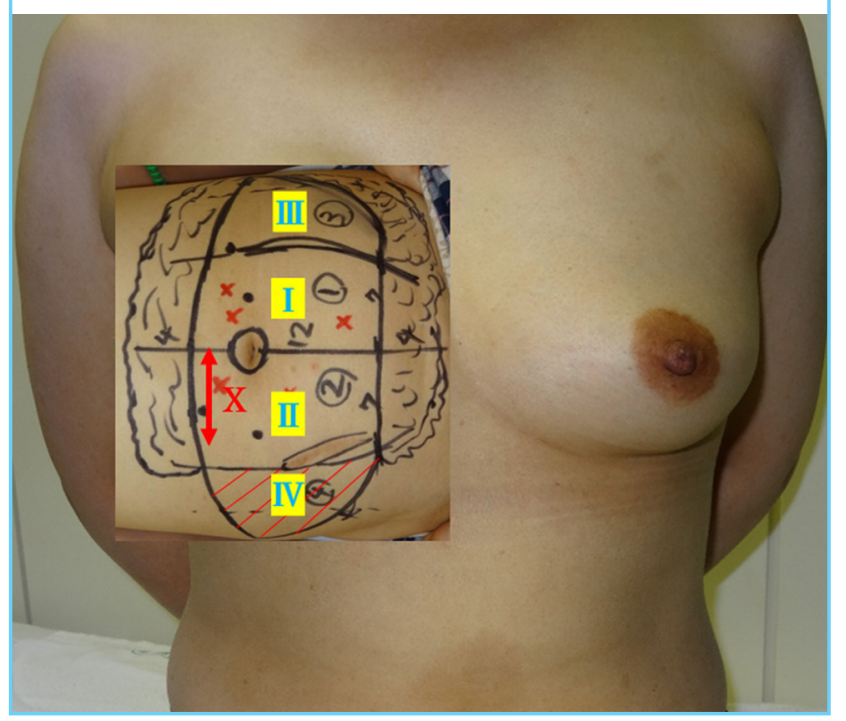

\section{Sample preoperative calculation of the flap volume}

For case 4, the following calculation was performed. We harvested the TRAM flap with a muscle-sparing technique (type 1). We measured the width and height of each zone using a ruler, and measured the thickness using ultrasound (Fig. 3A). The flap volume of zone I was calculated as a square prism (Fig. 3B). Similarly, the flap volume of zone II was calculated as a square prism (Fig. 3C). The flap volume of zone III was calculated as a triangular prism (Fig. 3D). The adipose flap volume was calculated as the sum of three areas (upper and lower side of the TRAM flap, left side of the TRAM flap). The former two volumes were approximated as a square prism. The latter volume (left side of the flap) was approximated as a triangular prism (Fig. 3E). The total volume of the TRAM flap was calculated to be $330+36 \mathrm{X} \mathrm{cm}^{3}$. Considering postoperative atrophy, we determined the required flap volume to be $1.2 \times$ the mastectomy volume, and consequently, the required flap volume was $480 \mathrm{~cm}^{3}$. The equation was solved as follows: $330+36 \mathrm{X}=480, \mathrm{X}=4.2$. We thus predicted that we would need to resect approximately half of zone II preoperatively. We performed a similar calculation for all cases.

\section{Intraoperative adjustment and postoperative evaluation} The pedicle of the TRAM flap, containing deep epigastric vessels, was anastomosed to the internal thoracic vessels in an endto-end fashion. After reconstructing the IMF line, we adjusted the width of zone II in the sitting position, referring to the shape of the contralateral breast and considering the postoperative atrophy of the flap. After touch-up surgery was performed, if necessary, and at least 6 months after reconstruction with the TRAM free flap, we evaluated the aesthetic results according to three grades (good, fair, and poor). We also compared the estimated flap width of zone II $(=\mathrm{X})$ and the actual flap width of zone II.

\section{Ethics}

The protocol of this study was approved by the relevant Institutional Review Board (approval number: C-167), and all authors adhered to the STROBE (Strengthening the Reporting of Observational Studies in Epidemiology) guidelines. All patients provided written informed consent for the publication of this article.

\section{RESULTS}

There were no major complications related to reconstruction with the TRAM flap during the follow-up period. The dimensions and thickness of the flaps are shown in Table 2. Zone II width measurements based on preoperative calculations and af- 
Fig. 3. Sample preoperative calculation of flap volume

(A) Measurement of each part of the flap. The width of zones I and II was 7 and $5 \mathrm{~cm}$, respectively, and the height of the skin island was $12 \mathrm{~cm}$. The height of the adipose flap on the upper and lower sides of the transverse rectus abdominis myocutaneous (TRAM) flap was $4 \mathrm{~cm}$. The thickness of zones I and II was $2.2 \mathrm{~cm}$, on average; in this case, the thickness of zone I and II was $1.8 \mathrm{~cm}$, and that of the adipose flap was $1.2 \mathrm{~cm}$. (B) Calculated flap volume in zone I. The flap in zone I was approximated as a square prism (surrounded by the white line, length $[12 \mathrm{~cm}] \times$ width $[7$ $\mathrm{cm}] \times$ depth $[2.2 \mathrm{~cm}]=184.8 \mathrm{~cm}^{3}$ ). (C) Calculated flap volume in zone II. The flap in zone II was approximated as a square prism (surrounded by the white line, length $[12 \mathrm{~cm}] \times$ width $[X \mathrm{~cm}] \times$ depth $[2.2 \mathrm{~cm}]=26.4 X \mathrm{~cm}^{3}$ ). (D) Calculated flap volume in zone III. The flap in zone III was approximated as a triangular prism (surrounded by the white line, length $[12 \mathrm{~cm}] \times$ width $[5 \mathrm{~cm}] \times$ depth $[1.8 \mathrm{~cm}] \times$ $0.5=54 \mathrm{~cm}^{3}$ ). (E) Calculated volume of the adipose flap. The upper and lower sides of the adipose flap were approximated as a square prism $([4+4 \mathrm{~cm}] \times[7+X+5 \mathrm{~cm}] \times 1.2$ $\left.\mathrm{cm}=115.2+9.6 X \mathrm{~cm}^{3}\right)$, and the left side of the adipose flap was approximated as a triangular prism $(12 \mathrm{~cm} \times 5 \mathrm{~cm} \times 1.2 \mathrm{~cm} \times 0.5=36$ $\mathrm{cm}^{3}$ ). They are shown and surrounded by the white line.
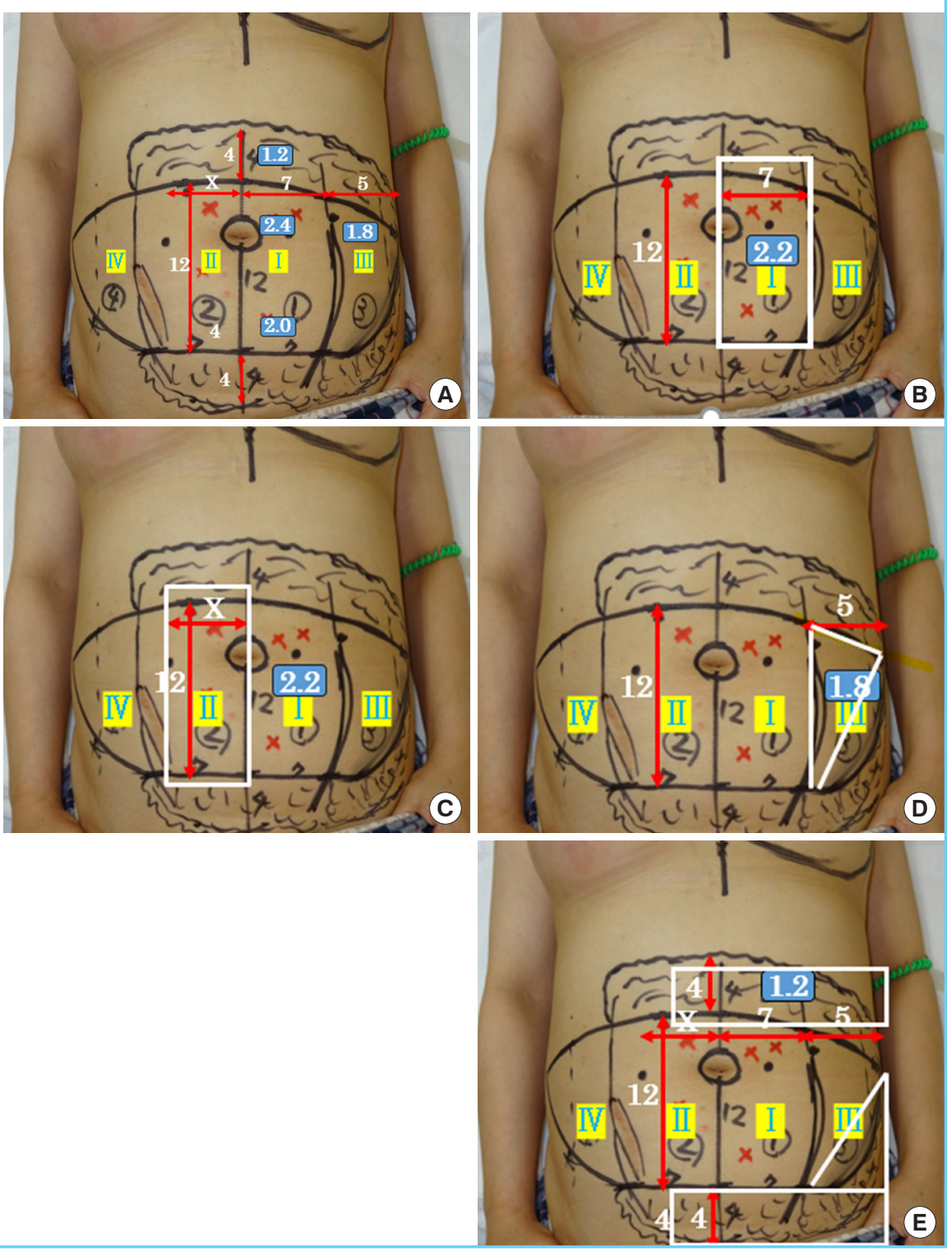

Table 2. Flap dimensions and thickness

\begin{tabular}{|c|c|c|c|c|c|}
\hline Case & $\begin{array}{l}\text { Flap dimensions } \\
W(\mathrm{~cm}) \times \mathrm{H}(\mathrm{cm})\end{array}$ & $\begin{array}{l}\text { Adipose flap } \\
\text { width (cm) }\end{array}$ & $\begin{array}{c}\mathrm{T}_{1} \\
(\mathrm{~cm})\end{array}$ & $\begin{array}{c}\mathrm{T}_{3} \\
(\mathrm{~cm})\end{array}$ & $\begin{array}{c}\mathrm{T}_{\mathrm{f}} \\
(\mathrm{cm})\end{array}$ \\
\hline 1 & $10 \times 20$ & $2.0-3.0$ & 2.0 & 1.5 & 0.9 \\
\hline 2 & $12 \times 24$ & 4.0 & 3.5 & 2.8 & 1.9 \\
\hline 3 & $12 \times 26$ & $1.0-5.0$ & 2.4 & 2.0 & 1.0 \\
\hline 4 & $12 \times 24$ & 4.0 & 2.2 & 1.8 & 1.2 \\
\hline 5 & $12 \times 24$ & 4.0 & 3.2 & 3.0 & 2.0 \\
\hline \multicolumn{6}{|c|}{$\begin{array}{l}\text { W, the maximum horizontal length of the transverse rectus abdominis } \\
\text { myocutaneous (TRAM) flap; } \mathrm{H} \text {, the maximum vertical length of the TRAM flap; } T_{1} \\
\text { the thickness of zone } \mathrm{I} ; \mathrm{T}_{3} \text {, the thickness of zone III; } T_{\mathrm{f}} \text {, the thickness of the } \\
\text { adipose flap. }\end{array}$} \\
\hline
\end{tabular}

ter intraoperative trimming, after touch-up surgery, and at the final follow-up are shown in Table 3. When the flap design was de- termined, it took approximately 10 minutes to measure each variable and to calculate the flap volume, including time for reconsideration. The estimated flap width of zone II $(=\mathrm{X})$ was similar to the actual flap width of zone II. Adjustment of the flap could be performed in approximately 15 minutes. For touch-up surgery, we performed minor revisions under local anesthesia. Fig. 4 shows a series of photographs from the clinical course of case 4, with an explanation of the sample preoperative calculation of the flap volume. Appropriate volume replacement with a TRAM flap resulted in good symmetry in all cases (Figs. 4D and 5).

\section{DISCUSSION}

CT, CT angiography (CTA), the pinch test, and ultrasound 
Table 3. Zone II width based on preoperative calculations and after intraoperative trimming, touch-up surgery, and results

\begin{tabular}{|c|c|c|c|c|c|c|}
\hline Case & $\begin{array}{l}\text { Calculated flap } \\
\text { volume }\left(\mathrm{cm}^{3}\right)\end{array}$ & $\begin{array}{l}\text { Required flap volume } \\
\qquad\left(\mathrm{cm}^{3}\right)\end{array}$ & $\begin{array}{c}X \\
(\mathrm{~cm})\end{array}$ & $\begin{array}{l}\text { Zone II width after } \\
\text { intraoperative } \\
\text { trimming }(\mathrm{cm})\end{array}$ & Touch-up surgery of flap & Result \\
\hline 1 & $235.2+27.2 X$ & 337 & 3.7 & 3.0 & $\begin{array}{l}\text { Monitor skin paddle resection }\left(10 \mathrm{~cm}^{3}\right) \text {, } \\
\text { fat graft }\left(10 \mathrm{~cm}^{3}\right)\end{array}$ & Good \\
\hline 2 & $616.0+58.0 \mathrm{X}$ & 894 & 4.8 & 4.7 & Monitor skin paddle resection $\left(15 \mathrm{~cm}^{3}\right)$ & Good \\
\hline 3 & $454.8+72.0 \mathrm{X}$ & 558 & 1.4 & 1.8 & $\begin{array}{l}\text { Monitor skin paddle resection }\left(15 \mathrm{~cm}^{3}\right) \text {, } \\
\text { cranial defatting }\left(15 \mathrm{~cm}^{3}\right)\end{array}$ & Good \\
\hline 4 & $330.0+36.0 \mathrm{X}$ & 480 & 4.2 & 4.5 & None & Good \\
\hline 5 & $530.0+58.4 X$ & 948 & 7.2 & 7.0 & None & Good \\
\hline
\end{tabular}

\section{Fig. 4. The clinical course of case 4}

(A) Preoperative chest view after full expansion. (B) Transverse rectus abdominis myocutaneous (TRAM) flap view after harvest. It was partially de-epithelialized and zone IV was excised. (C) The view of the donor site at postoperative month 6. (D) Photograph showing symmetrical breasts at postoperative month 6.
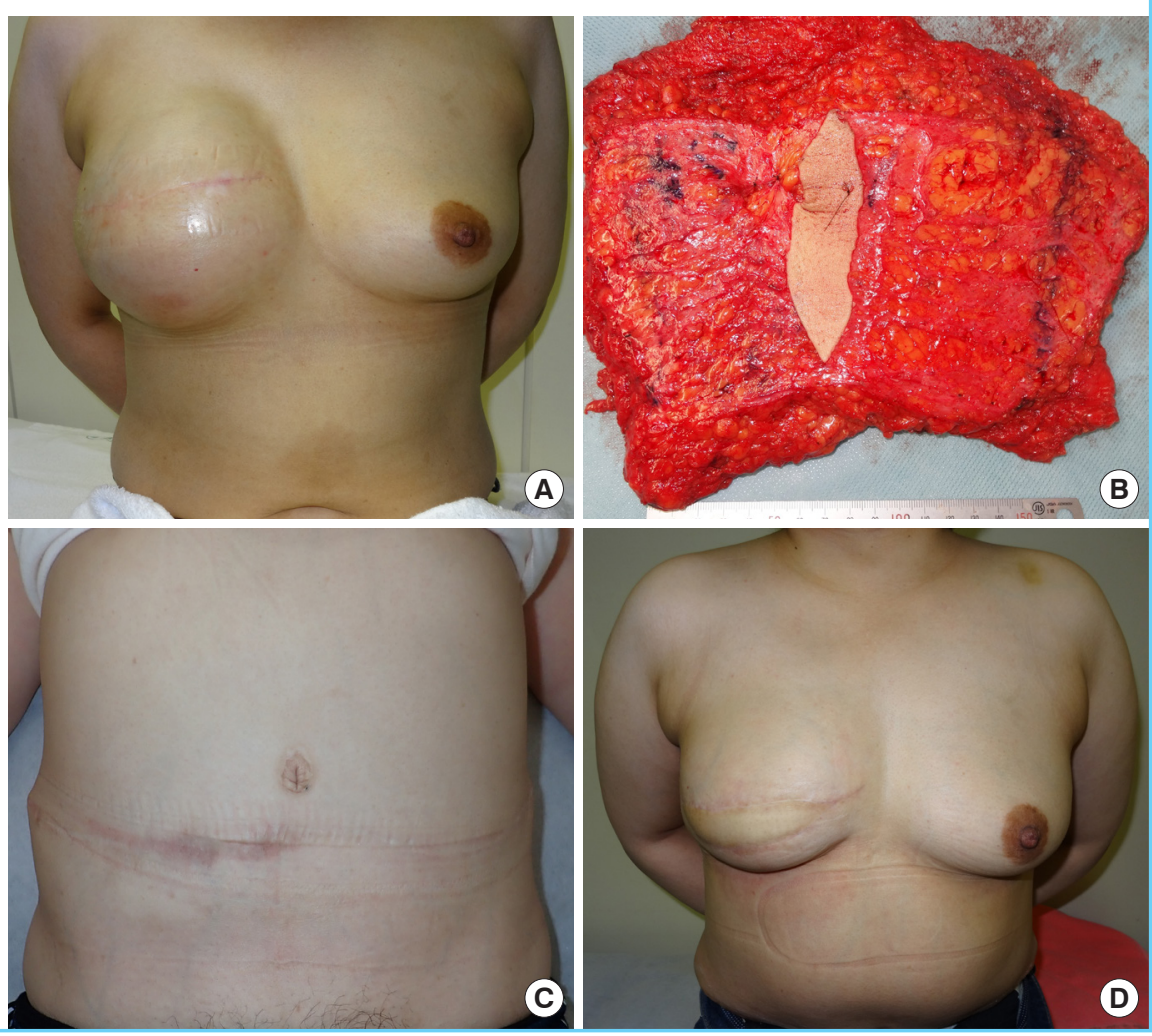

have been reported as methods of preoperatively estimating TRAM flap volume [4-7,9], and breast reconstruction using a mold of the contralateral breast made of a thermoplastic sheet has also been reported $[10,11]$. The use of CT or CTA has the merit of involving no interexaminer variance; however, these methods have the disadvantages of cost, being time-consuming and non-portable, and requiring exposure to radiation. The pinch test has the merit of being easy to perform if the appropriate device is available; however, interexaminer variance often occurs. The use of apps for CTA or the pinch test has recently been reported to be convenient, if Internet access is available [12]. We used ultrasound in the study in order to measure the abdominal skin thickness quickly. Ultrasound is portable and less expensive, although the probe should be used without skin compression to minimize interexaminer variance. A problem commonly identified in previous reports is that only the total TRAM flap volume could be estimated, not including adipose flaps; however, we were able to estimate the TRAM flap volume by defining the portion to be trimmed as a variable and including the adipose flaps.

A thermoplastic plastic sheet can be used to prepare a mold of the contralateral breast preoperatively and to resect the portion of the TRAM flap that protrudes from the mold intraoperatively. Although the intraoperative procedure is convenient, it takes 


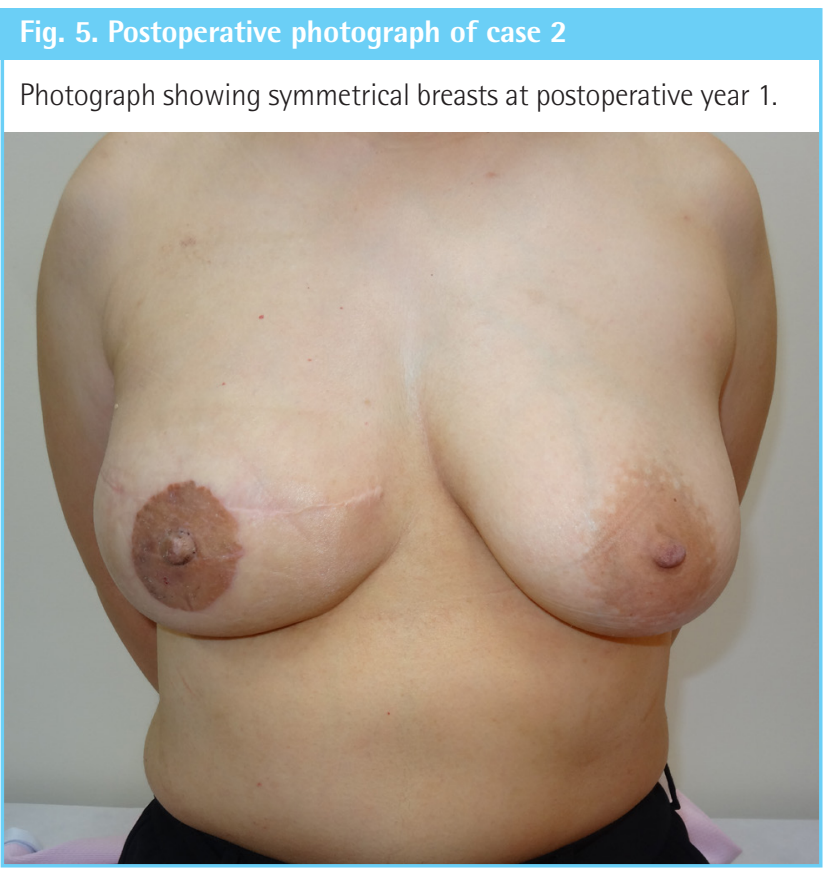

time and effort to create a mold, and the amount of flap resection cannot be predicted preoperatively. A simple and practical method of estimating flap volume prior to surgery has not been reported.

Our method can be easily performed using ultrasonography, a ruler, and simple calculations. Since we could estimate the flap volume and the resected flap length preoperatively based on the weight of the resected tissue from the mastectomy, it was possible to operate precisely in a short time frame. In fact, we only required approximately 15 minutes to adjust the flap. Therefore, our procedure is useful for designing the flap, because it allows excesses or deficiencies of flap volume to be detected preoperatively.

It is known that adjuvant chemotherapy and anti-estrogenic therapy can result in a decreased volume of the contralateral breast following mastectomy for breast cancer treatment [13]. We calculated the required flap volume as $1.2 \times$ the volume of resected tissue from the mastectomy, in order to reflect the volume change of the contralateral breast after adjuvant chemotherapy or postoperative body weight changes. Based on the expected volume change of the contralateral breast, the required flap volume should be adjusted accordingly.

The main limitation of our method is that it is an approximate calculation and proof of its accuracy is needed. Measurements of TRAM flap volume after trimming by water displacement and comparing the estimated flap volume with the measured flap volume may provide further evidence to support the results of the present study. Furthermore, our results using flap estimation should be compared to the results of procedures in which it was not used.

In a future study, we will apply our method to other TRAM flaps with various degrees of inclination, even though the calculations may become complicated. Furthermore, results are needed from a larger number of cases, and this issue should also be investigated through multicenter collaborative research. However, even at the present stage, the efficiency of the intraoperative adjustment was improved using these simple measurements and calculations.

We introduced a novel and simple method for calculating the volume of TRAM free flaps and preoperatively predicting the amount of flap trimming required based on the weight of the resected tissue from the mastectomy. The width of zone II based on the preoperative calculations was similar to the actual flap width of zone II after trimming in all cases. Regarding the aesthetic results, in all cases, the patients showed cosmetically acceptable, symmetrical breasts. We consider our procedure to be easy to perform, and it may contribute to increased time efficiency when tailoring flaps precisely.

\section{NOTES}

\section{Conflict of interest}

No potential conflict of interest relevant to this article was reported.

\section{Ethical approval}

The study was approved by the Institutional Review Board of Tochigi Cancer Center (IRB No. C-167) and performed in accordance with the principles of the Declaration of Helsinki. Written informed consents were obtained.

\section{Patient consent}

The patient provided written informed consent for the publication and the use of their images.

\section{REFERENCES}

1. Holmstrom $\mathrm{H}$. The free abdominoplasty flap and its use in breast reconstruction: an experimental study and clinical case report. Scand J Plast Reconstr Surg 1979;13:423-7.

2. Wang XL, Liu LB, Song FM, et al. Meta-analysis of the safety and factors contributing to complications of MS-TRAM, DIEP, and SIEA flaps for breast reconstruction. Aesthetic Plast Surg 2014;38:681-91.

3. Selber JC, Samra F, Bristol M, et al. A head-to-head comparison between the muscle-sparing free TRAM and the SIEA flaps: is the rate of flap loss worth the gain in abdominal wall 
function? Plast Reconstr Surg 2008;122:348-55.

4. Rosson GD, Shridharani SM, Magarakis M, et al. Three-dimensional computed tomographic angiography to predict weight and volume of deep inferior epigastric artery perforator flap for breast reconstruction. Microsurgery 2011;31:5106.

5. Kim H, Lim SY, Pyon JK, et al. Preoperative computed tomographic angiography of both donor and recipient sites for microsurgical breast reconstruction. Plast Reconstr Surg 2012;130:11e-20e.

6. Eder M, Raith S, Jalali J, et al. Three-dimensional prediction of free-flap volume in autologous breast reconstruction by CT angiography imaging. Int J Comput Assist Radiol Surg 2014;9:541-9.

7. Woo KJ, Mun GH. Estimation of DIEP flap weight for breast reconstruction by the pinch test. Microsurgery 2017;37:78692.

8. Yano K, Hosokawa K, Nakai K, et al. Regional differences in ultrasonic assessment of subcutaneous fat thickness in the abdomen: effects on the TRAM flap. Ann Plast Surg 2003; 51:130-5.

9. Minn KW, Hong KY, Lee SW. Preoperative TRAM free flap volume estimation for breast reconstruction in lean patients. Ann Plast Surg 2010;64:397-401.

10. Campaigne BN, Katch VL, Freedson P, et al. Measurement of breast volume in females: description of a reliable method. Ann Hum Biol 1979;6:363-7.

11. Edsander-Nord A, Wickman M, Jurell G. Measurement of breast volume with thermoplastic casts. Scand J Plast Reconstr Surg Hand Surg 1996;30:129-32.

12. Woo KJ, Kim EJ, Lee KT, et al. A novel method to estimate the weight of the DIEP flap in breast reconstruction: DIEPW, a simple calculation formula using paraumbilical flap thickness. J Reconstr Microsurg 2016;32:520-7.

13. Ishii N, Ando J, Harao M, et al. Decreased contralateral breast volume after mastectomy, adjuvant chemotherapy, and antiestrogen therapy, in particular in breasts with high density. J Plast Reconstr Aesthet Surg 2017;70:1363-8. 